\title{
Fibrocalculus Pancreatic Diabetes in a Young Female: A Rare Form of Secondary Diabetes
}

Bijaya Mohanty*, Prasad SK and Narain Pandey

Department of Medicine, Tata Main Hospital, Jamshedpur, India

Keywords: Fibrocalculus pancreatic diabetes (FCPD); Cyanosis; Carbohydrates; Alcohol; Diagnosis

\section{Introduction}

Fibrocalculus pancreatic diabetes (FCPD) is a rare form of diabetes. FCPD is one of the two forms of malnutrition related diabetes mellitus (MRDM), the other one being protein deficient diabetes mellitus (PDDM). Fibrocalculus pancreatic diabetes was introduced for this form of diabetes by the World Health Organization study group report on diabetes [1]. Several case reports of FCPD have been described in literature from tropical, poverty striken African [2,3] and Asian [4,5] countries for over 50 years. In India most cases are reported from Southern and Eastern India specifically from Kerala, Chennai and Odisha. From Jharkhand it is not reported.

Tropical calcific pancreatitis (TCP) is a unique form of juvenile onset, non-alcoholic, chronic pancreatitis peculiar to tropical countries. These patients present with intermittent episodes of pain abdomen typical of pancreatitis in childhood. Diabetes is one of the common end points of TCP. Various terminologies have been proposed for this form of diabetes including pancreatic diabetes, pancreatogenous diabetes and tropical pancreatic diabetes.

\section{Case Summary}

A 23 year old lady admitted to our hospital with history of a generalized weakness and pain abdominal of and on for two years. Pain was mild and present all over the abdomen. She also had a history of polyuria and polydipsia for five months. She was diagnosed as type 1 diabetes mellitus by local practitioner and treated accordingly. She had stopped the medication for two days and admitted with high blood sugar level along with pain abdomen.

All her family members were healthy. Nobody had diabetes or hypertension. She does not take alcohol or tobacco in any form. She belongs to low socio economic status. She consumes a balanced diet as far as practicable but gives a history that in childhood her principal diet was predominantly rich in carbohydrates.

On examination she was conscious, alert, febrile. There was mild pallor but no icterus, cyanosis or clubbing was noted. There was no lymphadenopathy or parotid gland enlargement. Skin was normal. Her body mass index was low (17.2 kg/meter square). Abdomen was soft. There was no organomegaly. There was mild tenderness over epigastrium. Neurological examination was normal.

At the time of presentation random blood sugar was $475 \mathrm{mg} / \mathrm{dl}$. The complete blood picture revealed mild leucocytosis of 13600/cumm (Normal 4000-10000). Her haemoglobin was $13.2 \mathrm{gm} / \mathrm{dl}$, platelet count was 296000 / cumm. Her HbA1C level was 9.5, total serum protein level was $7.92 \mathrm{mg} / \mathrm{dl}$. Her kidney and liver function tests were normal. Serum lipid levels were very low (Serum cholesterol-125.0, LDL-79.76, HDL34.8 , VLDL-10.44, serum triglyceride was $52.2 \mathrm{mg} / \mathrm{dl}$ ) Urine analysis showed glycosuria, mild proteinuria. Urine for ketones was absent. The stool analysis revealed no fat globules, ova or cysts. Examination of fundus was normal. ECG showed normal sinus rhythm. Chest $\mathrm{x}$-ray was normal.
The plain X-Ray of abdomen revealed multiple pancreatic calcifications (Figure 1). Ultrasonography of abdomen showed diffuse calcifications in the head, body and tail of the pancreas. CT abdomen was done which confirmed the findings of Plain X-Ray abdomen and USG abdomen (Figure 2). She was diagnosed a case of FCPD based on above clinical features and investigation results.

The patient achieved good glycaemic control with fixed dose combination of insulin 20 IU with breakfast and $10 \mathrm{IU}$ with dinner. She was also treated with pancreatic enzyme tablets with meals along with vitamins and calcium supplementation.

She was adequately counseled on the features of both hypo and hyperglycaemia. She was counseled regarding diet and self-blood glucose monitoring. She was discharged in a stable condition.

\section{Discussion}

Fibrocalculous pancreatic diabetes is very rare in the present scenario. Here we report a case of young female patient presenting with the clinical features of FCPD. Classic form of FCPD as described by Geevarghese has several distinct characteristics. Usually diagnosis of diabetes mellitus is made in the majority of patients between the ages of 10 years and 40 years ( 21 yrs in our case). There is a marked male preponderance. Extreme emaciation, a peculiar cyanotic hue of the lips, bilateral parotid gland enlargement and distension of the abdomen are some of the classic clinical feature [6-8]. However in our case she

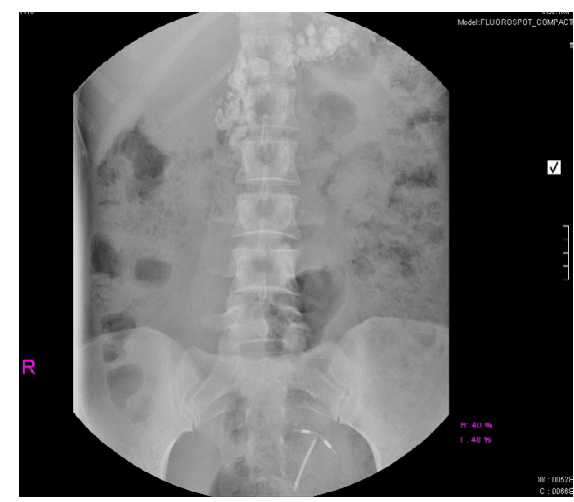

Figure 1: Straight X-Ray of abdomen showing multiple pancreatic calculi.

*Corresponding author: Bijaya Mohanty, Department of Medicine, Tata Main Hospital, Jamshedpur, India, Tel: +91-657 6641205, +91 7763807140; E-mail: bijayamohantytmh@gmail.com

Received: March 09, 2016; Accepted: April 28, 2016; Published: April 30, 2016

Citation: Mohanty B, Prasad SK, Pandey N (2016) Fibrocalculus Pancreatic Diabetes in a Young Female: A Rare Form of Secondary Diabetes. Diabetes Case Rep 1: 105. doi: 10.4172/2572-5629.1000105

Copyright: ( $) 2016$ Mohanty B, et al. This is an open-access article distributed under the terms of the Creative Commons Attribution License, which permits unrestricted use, distribution, and reproduction in any medium, provided the original author and source are credited. 

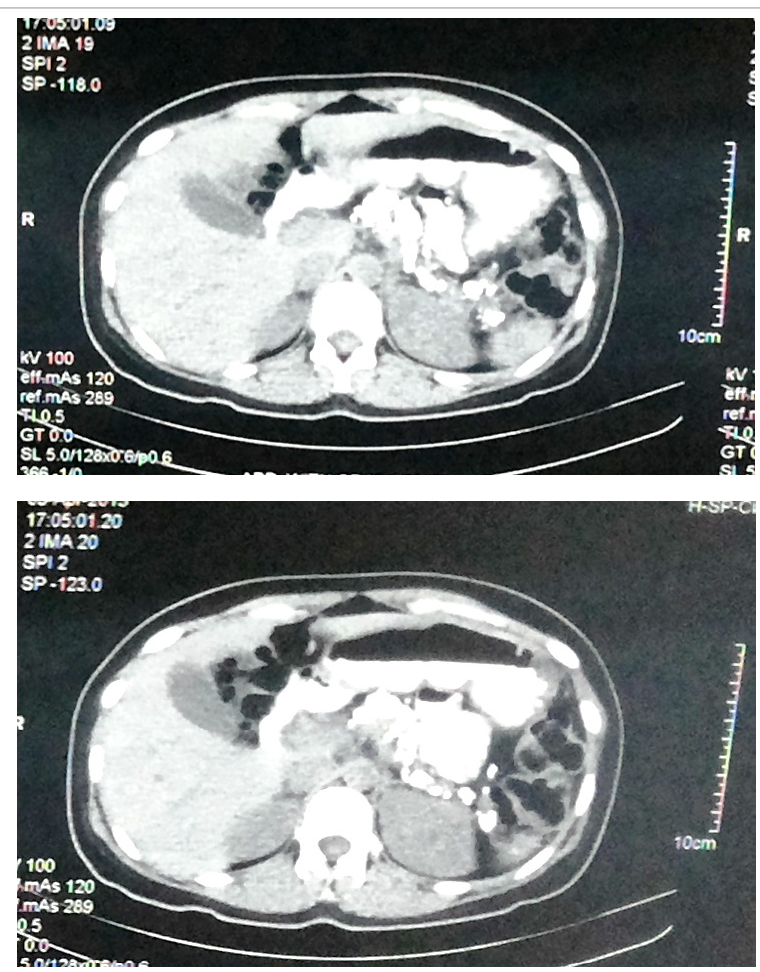

Figure 2: CECT Abdomen showing multiple calculi in the parenchyma and pancreatic duct.

was not emaciated though had a low BMI. There was no cyanosis also. Recently however there appears to be a change in the clinical features of the disease, perhaps because of the better nutritional status of the people. In a series by Dr Mohan et al. malnutrition was observed only in $25 \%$ of cases although $70 \%$ were lean. Now a days patients are also seen from middle and upper strata of society as well $[9,10]$. Many patients give a past history of recurrent episode of abdominal pain in childhood or adolescence suggestive of relapsing pancreatitis. The pain is usually severe, epigastric in location and characterized by periods of remission and exacerbation. It radiates to the back on either side and is typically relieved by stooping forward or lying in a prone position. The pain usually abates by the time diabetes sets in. In our patient abdominal pain was generalized and was mild in nature. The pain started at the age of 21 yrs. About one third of patients complain of passing bulky or oily stools. Stool was normal in our case. The low frequency of steatorrhoea has been attributed to low fat content of the diet. When the fat content of the diet was experimentally increased, steatorrhoea occurred in over $90 \%$ of patients [11]. Multiple factors have been thought to be associated with FCPD. These include malnutrition; toxic effects of cyanide derived from frequent cassava consumption, familial aggregation, genetic factors and increased oxidant stress from micronutrient deficiency (Vitamin $\mathrm{C}$ and A deficiencies).

Genetic factors have been proposed as the most significant in the etiology of FCPD. Current evidence has confirmed a link between the serine protease inhibitor, Kazal type (SPINK 1) gene and TCP [12,13]. It is a vital protease inhibitor that prevents unregulated or inappropriate activation of the pancreatic enzyme cascade by inhibiting trypsin activity [14]. Those would eventually result in to recurrent pancreatitis.

Demonstration of hyperglycaemia and pancreatic calculi on plain abdominal X-Ray, abdominal computed tomography scan confirms the diagnosis as shown in the patient discussed.

The diabetes is usually severe. Most patients require insulin for control of blood sugar. Interestingly despite requiring insulin for the control of diabetes, patients with FCPD rarely develop ketoacidosis even if insulin injections are withdrawn for prolonged periods. This happened in our case. Though she had stopped insulin for few days. She presented with hyperglycaemia but no ketoacidosis. This is probably because of the residual pancreatic beta cell reserve, a low glucagon reserve and decreased adipose tissue mass.

Other complications namely sight-threatening forms of retinopathy, maculopathy do develop in FCPD patients. In contrast macrovascular complications are less common [15], perhaps owing to the relative young age of the patients, their leanness and the low cholesterol levels [16,17]. Neuropathy, nephropathy and left ventricular dysfunction also occur.

\section{Conclusion}

Though rare FCPD still exists in developing countries. Recognizing such cases is very important. It should be thought of in the settings of young diabetes with pain abdomen especially in people with malnutrition. Tight glycaemic control, frequent blood glucose monitoring is the corner stone of management which will help in preventing complications. Awareness of this condition is necessary so as to detect the disease at the stage of chronic calcific pancreatitis before they develop significant beta cell loss leading to diabetes mellitus.

\section{References}

1. Diabetes mellitus. Report of a WHO Study Group (1985) World Health Organ Tech Rep Ser 727: 1-113.

2. Shaper AG (1960) Chronic pancreatic disease and protein malnutrition. The Lancet 275: 1223-1224.

3. Pitchumoni CS (1984) concepts and classification, Tropical or nutritiona pancreatitis: An update. Elsevior, Amsterdam, UK.

4. Geevarghese PJ (1968) Pancreatic diabetes. Bombay: Popular prakashan, India

5. Geevarghese PJ (1985) Calcific pancreatitis. Bombay, Varghese, India.

6. Viswanathan M, Sampath KS, Sarada S, Krishnaswami CV (1973) Etiopathology and clinical profile of pancreatic diabetes from Madras. J Assoc Phys Ind 21: 753-759.

7. Viswanathan M (1980) Pancreatic diabetes in India: An overview, The spectrum of diabetic syndromes. Secondary diabetes. Raven press, New York, USA

8. Mohan V, Mohan R, Susheela, Snehalatha C, Bharani G, et al. (1985) Tropica pancreatic diabetes in South India: heterogeneity in clinical and biochemical profile. Diabetologia 28: 229- 232.

9. Narendranathan M (1981) Chronic calcific pancreatitis of the tropics. Trop Gastroenterol 2: 40-45

10. Ramachandranan M, Pai KN (1977) Clinical features and management of pancreatic diabetes, Diabetes Mellitus. Arnold Heinemann, New Delhi, India.

11. Mohan V, Alberti KGMM (1991) Diabetes in the tropics, International text book of diabetes Mellitus. John Wiley \& sons Ltd, Chichester, UK.

12. Hassan Z, Mohan V, Ali L, Allotey R, Barakat K, et al. (2002) SPINK1 Is a major gene for susceptibility to fibrocalculus pancreatic diabetes in subjects from southern Indian sub continent. Am J Hum Genet 71: 964-968

13. Bhatia E, Choudhuri G, Sikora SS, Landt O, Kage A, et al. (2002) Tropical calcific pancreatitis : strong association with SPINK1 Trypsin inhibitor mutations Gastroenterology 123: 1020-1025.

14. Whitcomb DC, Gorry MC, Preston RA, Furey W, Sossenheimer MJ, et al. (1996) Heriditary pancreatitis is caused by a mutation in the cataionic trypsinogen gene. Nat Genet 14: 141-145.

15. Mohan V, Ramachandranan A, Viswanathan M (1989) Two case reports of macrovascular complications in fibrocalculus pancreatic diabetes. Acta Diab Lat 26: 345-346.

16. Mohan V, Farooq S, Deepa M (2008)Prevalence of fibrocalculus pancreatic diabetes in Chennai in south India, J of Pancrease 9: 489-492.

17. Kibirige D, Kibudde S, Mutebi E (2012) Fibrocalculous pancreatic diabetes in a young Ugandan patient, a rare form of secondary diabetes. BMC Research notes 5: 622 . 